\title{
ФАКТОРЫ, СПОСОБСТВУЮЩИЕ ВНЕДРЕНИЮ ИННОВАЦИЙ В РОССИЙСКУЮ СИСТЕМУ ЭЛЕКТРОННЫХ ЗАКУПОК
}

\section{() 2020 Орлова Лидия Сергеевна}

преподаватель Департамента менеджмента и инноваций, Факультета «Высшая школа управления» Финансовый университет при Правительстве РФ, Россия, Москва

E-mail: lsorlova@fa.ru

В статье рассматриваются факторы, влияющие на внедрение, использование и производительность системы электронных закупок. Описывается необходимость проведения цифровизации процессов закупочной деятельности. Представляются основные определения «электронных закупок», выявленные при обзоре литературы. Автором предлагается собственная классификация факторов, влияющих на российскую систему электронных закупок. Актуальность статьи определяется необходимостью внедрения новых технологий в российскую систему электронных закупок, а также вовлечения всё большего числа компаний к участию в ней.

Ключевые слова: государственные закупки, электронные закупки, блокчейн, факторы

Система государственных закупок играет большую роль в экономике страны, доля государственных закупок в общей сумме расходов бюджета составляет больше 30\%. Сфера государственных закупок играет большую роль в экономике страны. С помощью повышения эффективности системы можно добиться более оптимального расходования бюджетных средств. Основными проблемами контрактной системы государственных закупок на настоящее время являются коррупция, бюрократизированность процессов, неоднозначность правовых актов, её регулирующих.

Как и многие сферы государственного управления, российская система государственных закупок постепенно переходит в цифровой формат. Применительно к системе закупок переход к цифровой экономике означает перенос бюрократических процедур в цифровой формат, цифровизация процессов закупочной деятельности, анализ данных системы как для государственных, так и для коммерческих нужд. Российская система государственных закупок делает определённые шаги в сторону цифровизации и развивается аналогично принятым европейским стандартам. В первую очередь, была внедрена электронная государственная платформа (e-GP) Единая информационная система (ЕИС). Следующим шагом был переход от традиционных закупок, основанных на ценах, к записи данных и транзакций с использованием ЕИС. В 2017 году был издан Ф3 № 504, запретивший любые формы бумажных закупок. А с 1 января 2019 года все конкурентные процедуры были в обязательном порядке переведены в электронный формат [3, с.37-38].

Однако российская система сильно отстаёт от зарубежных во внедрении новейших технологий Индустрии 4.0, таких как интернет вещей, искусственный интеллект, большие данные, машинное обучение, блокчейн. Внедрение этих технологии позволит России решить различные проблемы. Так, например, одной из основных проблем российской экономики является коррупция, в том числе при осуществлении государственных закупок. Согласно международной организации Transparency International уровень коррупции в стране остаётся на высоком уровне и не имеет тенденции к снижению [13]. Так, в 2019 году страна занимала 137 место из 198 стран в рейтинге восприятия коррупции в государственном секторе, лидерами которого являются страны, в которых уровень коррупции находится на самом низком уровне. Технологии Индустрии 4.0 позволят России улучшить свои показатели, а значит и повысить уровень инвестиционной привлекательности страны. Помимо этого, они могут способствовать резкому скачку экономического развития, ведь на данный момент объем государственных закупок соответствует около 30\% ВВП РФ. Дальнейшее развитие системы государственных закупок немыслимо без внедрения данных технологий, ведь они позволят повысить прозрачность системы, улучшить условия доступа для новых участников, таким образом улучшив конкурен- 
цию между ними. Надо сказать, что с помощью цифровизации государственных закупок за счёт оптимального расходования административных ресурсов и усиления конкуренции снижение государственных расходов может достигать 20\%, а экономия времени работников сферы составит 80\%. Современное российское законодательство обязывает при рассмотрении заявки участника закупки проверять его только на предмет общей и специальной правоспособности и дееспособности. А это по оценке экспертов всего 10\% от той информации, которая необходима заказчику для правильного выбора добросовестного поставщика. А недобросовестные поставщики могут участвовать в государственных закупках, даже не сообщая полной информации о предыдущих нарушениях. Единый реестр участников закупок (ЕРУЗ) - первая ступенька для решения этой проблемы, однако без дальнейшего внедрения современных технологий, сбор дополнительной информации о поставщиках будет слишком дорогостоящей и трудоёмкой процедурой [12]. Всё это позволит существенно сократить государственные расходы. Таким образом актуальность данной статьи заключается в выделении основных направлений развития российской системы государственных закупок.

Одна из важнейших частей ведения бизнеса в сегодняшней конкурентной среде являются закупки. Закупки включают в себя функцию управления бизнесом, которая обеспечивает идентификацию, поиск, доступ и управления внешними ресурсами, которые необходимы организации или могут потребоваться для достижения её стратегических целей. Единого определения электронных закупок не существует, можно выделить следующие определения, обнаруженные в ходе обзора литературы. Согласно индийским исследователям Чопра и др., «электронные закупки - это практика закупок, в которой используется электронная коммерция для поиска возможных источников поставок, приобретения товаров и услуг, перевода платежа и связи с поставщиками» [7, с. 55]. Группа исследований под руководством Абердин и др. определила электронные закупки как «создание частных интернет-рынков закупок, которые автоматизируют коммуникации, транзакции и сотрудничество между партнерами по цепочке поставок» [4]. Однако, согласно Всемирному банку, электронные закупки определяются как «использование информационных технологий при установлении отношений закупок с по- ставщиками для закупки товаров и услуг» [11]. Бейли и др. определяют электронные закупки как «использование электронных методов на всех этапах процесса покупки, от определения требований до оплаты и, возможно, до управления контрактами» [6]. Это также понимается как использование электронных коммуникаций и обработки транзакций государственными учреждениями при покупке товаров и услуг или проведении общественных работ.

Внедрение информационных технологий и более интегрированных программных систем значительно улучшило способ заключения деловых контрактов между сторонами. Интернет кардинально изменил способ ведения бизнеса в мире. Он увеличил долю рынка, например, расширил охват клиентов, а также снизил стоимость своих пользователей. Еще одна область, в которой внедрение Интернета и инструментов ИКТ оказало значительное влияние,- это скорость и эффективность, которые являются основополагающим принципом любой закупочной организации. Помимо этого, электронные закупки также повышают прозрачность и доступность тендерных возможностей в процедурах государственных закупок, а также препятствуют усилению конкуренции во всем мире, что способствует экономическому росту. Согласно отчету Азиатского банка развития, правительство и другие государственные учреждения, внедрившие процесс электронных закупок, получили многочисленные целевые преимущества, такие как повышенная прозрачность, уведомления о заключении контрактов, онлайн-подача заявок и более широкое участие участников торгов за счет улучшенной информации и доступа. к возможностям [5]. Другие преимущества включают более быструю обработку закупочной деятельности благодаря онлайн-системе, усовершенствованные инструменты для борьбы с коррупцией и мошенничеством, а также сокращение количества печатных копий для документирования деловых операций. Традиционные системы закупок в государственном секторе страдали от различных проблем, таких как неоправданные задержки в обработке тендеров, тяжелая бумажная работа, физические угрозы участникам торгов, человеческий интерфейс на каждом этапе, низкая прозрачность, дискреционное отношение ко всему тендерному процессу и коррупция.

Эти уязвимости могут использоваться в различных коррупционных действиях, таких как хищение, неправомерное влияние на оценку по- 
требностей, подкуп государственных должностных лиц, участвующих в процессе присуждения контрактов, или мошенничество при оценке предложений, счетах-фактурах или контрактных обязательствах. Сертифицированные институты закупок и поставок Австралии (CIPSA) выделили семь основных преимуществ, которые любая компания может получить в процессе закупок. К ним относятся надежность поставок, большая добавленная стоимость, улучшенное качество, снижение затрат, снижение риска, повышение эффективности и инноваций.

Исследователи Нанданкар и Сачан методом категоризации классифицировали факторы, влияющие на внедрение, использование и производительность электронных закупок, на 4 группы: «организационный контекст», «ИТ-контекст», «пользовательский контекст», «экологический контекст» [9]. Первая группа - это «организационный контекст», который фокусируется на том, как интеграция организационных целей, политики, приоритетов и ресурсов с системой электронных закупок влияет на её эффективность. К ним относятся такие факторы, как поддержка высшего руководства, система управления изменениями в компании, относительное преимущество и др. Топ-менеджмент компании определяет корпоративные ценности и культуры компании, в том числе касаемо внедрения новых технологий. Руководство, убежденное в необходимости инноваций, изменений, желающее участвовать в системе электронных закупок, способствует более быстрому и эффективному внедрению инноваций в данной компании. Данный эффект был доказан в многочисленных исследованиях. В исследованиях данных авторов было доказано, отсутствие понимания у руководства полезности цифровых технологий для компании является серьезным препятствием в их внедрении. Помимо этого, даже при желании руководства внедрять цифровые технологии, риски, имеющиеся при их внедрении, могут остановить их при принятии решения о внедрении цифрового процесса.

Наличие у компании системы управления изменениями способствует внедрению в данном предприятии новых технологий. Чем более сложной является технология, тем более важным становится фактор степени готовности персонала и его квалификация. Проведение в компании организационного обучения системе электронных закупок способствует более эффективному его внедрение, снизит степень сопротивления персонала, которая почти всегда сопровождает внедрение в компании чего-то нового. Люди привыкают к старым системам, технологиям, привычкам, находят исключительно недостатки в новшествах, что препятствует их внедрению. Понимание преимуществ технологии, знание её возможностей и умение её использовать способствует участию компании в системе электронных закупок.

Относительное преимущество новшества состоит в получении компании сверхвыгоды по сравнению с использованием существующей технологии. Компании способствуют ускорению внедрения у себя технологии с целью получения конкурентного преимущества. Таким образом, если компаниям очевидны преимущества и выгоды технологии, то вероятность внедрения ими цифрового продукта повышается. Для предприятий такими преимуществами электронных закупок могут быть: более быстрый ответ на нужды клиентов, сокращение расходов и увеличение прибыли.

Вторая категория - это «ИТ-контекст», в котором основное внимание уделяется важности надежной и эффективной ИТ-инфраструктуры, удобного технологического интерфейса и высококачественной информационной и исходной платформы для системы электронных закупок. В ходе обзора литературы были выявлены следующие факторы, относящиеся к этой группе: качество контента, скорость обработки информации, процедуры заказа, точность выполненного заказа и своевременность выполненного заказа. Менее часто упоминаются и исследуются: качество веб-дизайна, безопасность и аутентификация, системная интеграция и качество разработки программного обеспечения. Такие факторы могут быть дополнительно изучены в будущих исследованиях, чтобы лучше понять исследования факторы, влияющие на эффективность внедрения системы электронных закупок. В этой группе стоит отметить такой важный фактор, влияющий на эффективность внедрения инноваций, как совместимость, который отражает возможность интеграции новой технологии с существующей IT-инфраструктурой. Если степень совместимости ниже, то и вероятность внедрения сильно снижается. Помимо этого, важно, чтобы у персонала был опыт работы с аналогичными типами систем. Чем большим опытом обладают сотрудники, тем с меньшими препятствиями придётся столкнуться компаниям при внедрении технологий.

Третья категория - это «индивидуальный 
пользовательский контекст», в котором особое внимание уделяется важности человеческих факторов. Такие факторы, как «воспринимаемая полезность, воспринимаемая простота использования и доверие» используются почти в каждом исследовании, изучающем эффективность внедрения цифровых продуктов. Помимо этого, в данной категории употребляются такие факторы, как профессионализм персонала, корпоративная солидарность, внутреннее сопротивление, социальный фактор и воспринимаемая ценность. В будущих исследованиях можно будет дополнительно изучить эти факторы. Социальным фактором определяется как степень, с которой человек осознает, что важные для него люди считают, что этому человеку следует использовать новую систему. Эта конструкция может быть связана с репутацией или имиджем, с помощью которых пользователь будет воспринимать использование инноваций в области электронных закупок для повышения его или ее социального статуса. Начальство или коллеги предположили, что система может быть полезной для человека. Более вероятно, что восприятие индивида превратится в веру в то, что полезно и известно принимать информацию от другого человека, имеющего более высокий ранг. Навару и др. указали, что чем крупнее бизнес компании, тем больше вероятность того, что она будет использовать системы электронных закупок из-за социальных факторов [10].

Воспринимаемая простота использования связана с оценкой пользователем усилий, связанных с процессом использования системы. Он измеряется с точки зрения того, насколько четким и понятным является взаимодействие с системой электронных закупок, а также легкостью заставить систему электронных закупок выполнять то, для чего она предназначена. Когда компании меняют метод закупок, от пользователя требуется умственное усилие при взаимодействии с системой, это влияет на интерес пользователя к использованию системы.

Более того, пользователь не может в полной мере использовать какие-либо электронные услуги, если восприятие сотрудников не изменилось. Они будут сопротивляться изменениям и придут к выводу, что систему электронных закупок нелегко использовать. Короче говоря, пользователь согласится с электронными закупками, если сочтет, что система полезна и проста в использовании.

Воспринимаемая полезность относится к степени, с которой человек считает, что использование системы электронных закупок повысит производительность труда человека. Таким образом, воспринимаемая полезность относится к убеждению, что электронные закупки помогут человеку выполнить задачу легче, чем он / она в настоящее время может делать с текущими системами закупок.

Четвертая категория - это «экологический контекст», представляющий деловой климат, в котором осуществляется деятельность организации. К ним относятся давление конкурентов, давление торговых партнёров, тип бизнеса, уровень конкуренции, размер рынка, деятельность правительства, законы и постановления. Принятие цифровой технологии конкурентами или торговыми партнёрами способствует тому, чтобы компания эффективно внедрила это новшество. Никому не хочется терять клиентов только в связи отсутствием гибкости собственной системы. Помимо этого, компании можно принудить проводить только электронные закупки законодательно, что и делается в России. Однако методом принуждения нужно пользоваться аккуратно и внедрять технологии постепенно, так как компании могут не успеть приспособиться к новой системе. Также к четвертой группе факторов можно отнести неопределённость рынка, которая выражается в нестабильности спроса и предложения, политической ситуации. Однако данный фактор может вызвать два противоположных эффекта в зависимости от типа инновации. К первому относится нежелание компании инвестировать в новую технологию в связи с неопределённостью своего положения, ко второму относится стимулирование внедрения цифрового продукта в связи с желанием обрести конкурентное преимущество в нестабильное время. Также к факторам экологической группы можно отнести «прозрачность рынка», который отражает степень доступности информации о возможностях различных технологий. Если на рынке мало поставщиков технологий и их технологические продукты не связаны между собой, отсутствуют стандарты данный рынок не прозрачен и малым и средним компаниям будет сложно в нём разобраться. На прозрачном рынке в открытом доступе находится информация о возможностях различных технологических решений, об их характеристиках и стоимости.

Таким образом, можно сделать вывод, что при построении инновационной системы государственных закупок компании придется учесть 
очень большое количество факторов. Привлекательность системы и количество решаемых ею бизнес-задач способствует развитию системы электронных закупок. И тут хотелось бы упомянуть технологию, способную резко увеличить функциональность системы электронных закупок, а именно блокчейн. Блокчейн - это технология распределенной цифровой бухгалтерской книги, в которой транзакции, совершаемые в биткойнах или другой криптовалюте, регистрируются в хронологическом и публичном порядке [2]. Использование данной технологии позволяет ускорить процесс отбора контрагентов, ведь система может самостоятельно анализировать закупочные документы, управлять контрактами, проверять документы о закупках и квалификации участников закупок. К преимуществам данной технологии относятся прозрачность системы, так как участники закупок имеют возможность отследить любую транзакцию, а также конфиденциальность информации, которая обе- спечивается зашифрованностью данных. Можно выделить несколько барьеров при внедрении технологии блокчейна в систему закупок. Первым и самым главным препятствием является необходимость сбора и объединения данных всех участников договора: банков, контрагентов, государственных органов. Это достаточно трудои ресурсоёмкий процесс, который необходимо будет регулировать [1].

Во-вторых, препятствием может быть необходимость резервирования бюджетных средств, которое обеспечит самоисполняемость смартконтрактов. Также недостатком технологии является дороговизна её внедрения. Основные затраты составляют дорогостоящие специалисты в этой области, ведь технология относительно новая и еще недостаточное количество специалистов имеет достаточные навыки для разработки системы, что при относительно высоком спросе приводит к их высокой стоимости.

\section{Статья подготовлена по результатам исследований, выполненных за счет бюджетных средств по государственному заданию Финуниверситета.}

\section{Библиографический список}

1. Тарасов И.В. Подходы к формированию стратегической программы цифровой трансформации предприятия. Стратегические решения и риск-менеджмент. 2019;10(2):182-190

2. Трачук A.B., Линдер Н. В. Четвертая промышленная революция: как влияет интернет вещей на взаимодействие промышленных компаний с партнерами? Стратегические решения и риск-менеджмент. 2018;(3):1629; Хасанов А. Р. Влияние предиктивной аналитики на деятельность компаний. Стратегические решения и риск-менеджмент. 2018(3):108-113.

3. Шмелева М.В. Цифровые технологии в государственных и муниципальных закупках: будущее или реальность/ М. В.Шмелева // Актуальные проблемы российского права. 2019. № 12 (109) с. 36-42

4. Aberdeen Group (2013), Best Practices in E-Procurement: The Abridged Report, Aberdeen Group, Boston, MA.

5. Asian Development Bank (ADB) (2006) Economic \& Social Commission for and the Pacific Asian Development Bank Institute Public Procurement Service of the Republic of Korea, E-procurement, United Nations Publication, Thailand.

6. Baily P., Farmer D., Crocker B., Jessop D., Jones D. (2008) Procurement Principles and Management, 10th ed., Prentice Hall, Harlow, England.

7. Chopra S., Dougan D. and Taylor G. (2001), “B2B e-commerce opportunity”, Supply Chain Review, Vol. 5 No. 3, pp. $50-62$.

8. Hosseini S., Ivanov D. and Dolgui A. (2019), "Review of quantitative methods for supply chain resilience analysis", Transportation Research Part E: Logistics and Transportation Review, Vol. 125, pp. 285-307.

9. Nandankar S., Sachan A. (2020), «Electronic procurement adoption, usage and performance: a literature review», Journal of Science and Technology Policy Management, Vol. 11 No. 4, pp. 515-535

10. Navaroo, JGC, FW Dewhurst and AJB Penalver (2007). Factors affecting the use of e-government in the telecommunications industry of Spain. Technovation, 27(10), 595-604.

11. World Bank (2003) 'Procurement for projects and programs, e-procurement', Journal of Bank Procurement, Vol. 56, No. 1, pp.38-45.

12. Искусственный интеллект наведет порядок в системе закупок [Электронный ресурс] Режим доступа: https:// ac.gov.ru/news/page/iskusstvennyj-intellekt-navedet-poradok-v-sisteme-zakupok-25140

13. CPI 2019 TROUBLE AT THE TOP [Электронный ресурс] Режим доступа: https://www.transparency.org/en/news/ cpi-2019-trouble-at-the-top 